\title{
Relation of serum vitamin D level in polycystic ovarian syndrome (PCOS) patients to ICSI outcome
}

\author{
Eman Fawzy Omran 1* (D), Abdelmaguid Ramzy ${ }^{1}$, Amal Shohayeb', Nermeen Farouk1, Mahmoud Soliman', \\ Heba Baz ${ }^{2}$ and Marwa Foad Sharaf ${ }^{1}$
}

\begin{abstract}
Background: Recently, vitamin D was discovered to have an important role in female reproduction and IVF. However, there were no studies specifically addressed its role in polycystic ovarian syndrome (PCOS) patients undergoing ICSI cycles. Therefore, this cross-sectional study in a university hospital was conducted to evaluate the effect of serum level of vitamin D (VD) on the number of retrieved and fertilized oocytes, and chemical and clinical pregnancy rate in PCOS females undergoing ICSI cycles. The study included 80 PCOS cases undergoing ICSI cycles in the age from 20 to 39 years using antagonist protocol. Cases with severe male or tubal factors were excluded. Serum $25(\mathrm{OH})$ D vitamin level was assessed by the ELIZA method on the day of oocyte retrieval. Correlation and regression analyses were used in the analysis.
\end{abstract}

Results: VD was positively correlated to both numbers of retrieved and fertilized oocytes $(r=0.35,95 \% \mathrm{Cl} 0.15$, $0.53, P=0.001 ; r=0.33 ; 95 \% \mathrm{Cl} 0.03,0.57, P=0.03$, respectively). It was still significantly correlated to the number of oocytes (coefficient $0.47 ; 95 \% \mathrm{Cl} 0.1,0.9 ; P=0.018$ ) and to the number of fertilized eggs (coefficient $0.3 ; 95 \% \mathrm{Cl}$ $0.02,0.58 ; P=0.03$ ) after adjusting for age, BMl, and type of ovulation-triggering agent. This means with each $2 \mathrm{ng} /$ $\mathrm{mL}$ increase in serum VD level, around one more egg will be retrieved. In addition, there will be one more fertilized oocyte with each $3 \mathrm{ng} / \mathrm{mL}$ increase in the vitamin level. However, no significant correlation was found between the vitamin level and the occurrence of chemical or clinical pregnancy.

Conclusions: Serum vitamin D level is positively correlated with the number of retrieved and fertilized oocytes in PCOS patients undergoing ICSI cycles.

Keywords: Vitamin D level, Polycystic ovaries, In vitro fertilization, Intra-cytoplasmic sperm injection

\section{Background}

Polycystic ovary syndrome (PCOS) is the commonest endocrine abnormality in women of reproductive age [1]. Moreover, it leads to many health problems throughout the woman's life [1]. Worldwide, the prevalence of PCOS is 613\% [2]. In Egypt, it is estimated that the prevalence of PCOS is $13 \%$ in fertile and $37.5 \%$ in secondary infertile patients [3].

\footnotetext{
* Correspondence: eman.omran@kasralainy.edu.eg

1 Department of Obstetrics and Gynecology, Faculty of Medicine, Cairo University, Al-Saray St., Al-Manial, Cairo 11956, Egypt

Full list of author information is available at the end of the article
}

IVF/ICSI is considered an important line of management for anovulatory infertility in PCOS if lifestyle modifications and usual ovulation induction had failed to achieve pregnancy or the patient has other factors of infertility requiring IVF, such as severe male factor of infertility or tubal occlusion $[4,5]$.

In the past decade, vitamin $\mathrm{D}$ was discovered to have an important role in many parts of the body in addition to the classical sites of the bone, kidney, and intestine [6]. In particular, vitamin $\mathrm{D}$ was found to be involved in the regulation of several hormones in the body including the anti-Müllerian hormone (AMH) [7], follicle-stimulating 
hormone, estradiol, and progesterone [8]. In addition, a correlation was suggested between vitamin D deficiency and PCOS. This relation may be due to the effects of vitamin D receptors on $\mathrm{LH}$ and sex hormone-binding globulin levels, the incidence of insulin resistance, testosterone levels, and aromatase gene expression [9-14].

There has been an increasing interest recently in the investigation of the role of vitamin D in IVF due to the effects of vitamin D receptors on LH and sex hormonebinding globulin levels, the incidence of insulin resistance, testosterone levels, and aromatase gene expression [9-14]. However, the results of such research studies were inconsistent [6]. Moreover, no studies evaluated the effect of VD status on IVF/ICSI outcomes in PCOS females who represent an important category of cases undergoing assisted reproduction.

Therefore, we investigated the relation between serum $25(\mathrm{OH}) \mathrm{D}$ vitamin level and the outcome of ICSI cycles in PCOS cases.

\section{Methods}

This cross-sectional study was conducted in the IVF Unit of Cairo University from November 2016 to January 2018. It was approved by our institution's research ethics committee. The ethical standards of the Declaration of Helsinki were followed, and informed consents were taken from the study participants. Collection and reporting of data followed the guidelines of the STROBE checklist for observational studies [15].

The study population were 80 females who had PCOS and were scheduled to do ICSI cycles. They were in the age between 20 and 39 years and had a body mass index (BMI) between 20 and $29 \mathrm{~kg} / \mathrm{m}^{2}$. Females who had medical disorders, concomitant tubal factor, endometriosis, or severe uterine factor of infertility (intrauterine adhesions) were excluded. In addition, women who were taking vitamin $\mathrm{D}$ supplements or whose husbands had severe male factor (severe oligo-atheno-teratospermia or azoospermia) were excluded. PCOS was diagnosed in our patients following the Rotterdam criteria [16]. The indication for ICSI was the failure of previous ovulation induction cycles to achieve pregnancy [4].

History and general and local examinations were done for all patients. Vaginal or cervical infections (if present) were treated first before the ICSI cycle. Basal (day 2 or 3 of menstruation or withdrawal bleeding in case of oligomenorrhea) hormonal profile (as a part of the diagnosis for PCOS if the criteria were not fulfilled by clinical picture alone) was assessed for all women. Screening for hepatitis B, hepatitis $\mathrm{C}$, and HIV was performed before the start of the ICSI cycle.

Antagonist protocol was chosen for ovarian stimulation [4]. The details of the antagonist protocol followed our IVF unit protocol. Ovarian stimulation started on the second or third day of menstruation (or progestogen withdrawal) by $150 \mathrm{IU}$ subcutaneous human menopausal gonadotropin (HMG) (Merional, IBSA, Lugano, Switzerland). The first folliculometry was done 5 days after the start of stimulation, then it was done every 2 to 3 days. Gonadotropin-releasing hormone antagonist (GnRH antagonist) (Cetrotide, Merck Serono, Darmstadt, Germany) was started in a fixed manner $(0.25 \mathrm{mg}$ daily) from the 6th day of ovarian stimulation. Ovulation trigger was done by intra-muscular $5000 \mathrm{IU}$ of urinary human chorionic gonadotropin (HCG) (Choriomon, IBSA, Lugano, Switzerland) when 3 follicles reached 17 $\mathrm{mm}$. According to our IVF unit's policy, GnRH agonist triggering for ovulation (instead of HCG) and administration of dopamine agonist were done if serum estradiol was higher than $5000 \mathrm{pg} / \mathrm{mL}$ at the day of ovulation trigger. The GnRH agonist was in the form of subcutaneous $0.2 \mathrm{mg}$ of GnRH analog (Decapeptyl, Ferring, Saint-Prex, Switzerland). In addition, dopamine agonist (Dostinex, Pfizer, New York, NY, USA) $0.5 \mathrm{mg}$ /day orally for 8 days was given starting from the day of ovulation trigger. Oocyte retrieval was done 35-36 h after HCG (or GnRH agonist) injection.

Ultrasound-guided transfer of embryos was done on day 2 or 3 after oocyte retrieval (according to our IVF laboratory policy). Freezing of all embryos was done if 25 or more oocytes were retrieved [17]. Luteal phase support was started on the day of egg collection by twice daily 400 $\mathrm{mg}$ progesterone vaginal suppository intake (Cyclogest, Actavis, Barnstaple, UK). Daily $4 \mathrm{mg}$ of estradiol valerate (the white tablets of Cyclo-Progenova, Bayer HealthCare Pharmaceuticals LLC, Berlin, Germany) was added to daily progesterone in case of $\mathrm{GnRH}$ agonist triggering for ovulation (according to our unit protocol). Luteal phase support continued for 15 days until serum quantitative pregnancy test (bHCG) and for further 8 weeks in case of positive pregnancy.

Pregnancy was considered positive (biochemical pregnancy) if serum bHCG was more than $50 \mathrm{mIU} / \mathrm{mL}$. Clinical pregnancy was reported if a gestational sac (or more) with fetal cardiac activity was seen by ultrasound 2 weeks after a positive pregnancy test.

\section{Vitamin D measurement}

Blood samples were collected at the day of oocyte collection. Two milliliters of blood was obtained and allowed to clot at room temperature. The blood tube was then centrifuged for $15 \mathrm{~min}$ at and was stored below $20{ }^{\circ} \mathrm{C}$ until assayed. ELISA test $(25 \mathrm{OH}$ vitamin D3/D2, ORGENTEC Diagnostika GmbH, Mainz, Germany) was used to measure serum $25(\mathrm{OH})$ D vitamin level. Measurement of serum vitamin $\mathrm{D}$ followed the manufacturer's instructions in the kit's leaflet. One hundred microliters of patient samples, calibrators, and controls 
was pipetted into wells and incubated for $30 \mathrm{~min}$ at room temperature $\left(20-30{ }^{\circ} \mathrm{C}\right)$. Then, the contents of the micro-wells were discarded and washed 3 times with $300 \mu \mathrm{l}$ of wash solution. Thereafter, $100 \mu \mathrm{l}$ of the enzyme conjugate was dispensed into each well and incubated for $15 \mathrm{~min}$ at room temperature. After another washing, $100 \mu \mathrm{l}$ of enzyme-substrate solution was dispensed into each well and incubated for $15 \mathrm{~min}$ at room temperature. Afterwards, $100 \mu \mathrm{l}$ of a stop solution was added to each well of the molecules and incubated for 5 min. The optical density at $450 \mathrm{~nm}$ was read, and the serum $25(\mathrm{OH})$ vitamin D level was interpreted accordingly in nanograms/milliliter.

The primary outcomes of the study were correlations of the serum vitamin $\mathrm{D}$ level to the number of retrieved oocytes and number of fertilized embryos resulting from ICSI cycle, while the secondary outcomes were correlation of serum vitamin $\mathrm{D}$ at the day of oocyte retrieval to the occurrence of chemical and clinical pregnancy in our study cohort.

\section{Sample size calculation}

Calculation was based on the correlation between the serum level of vitamin D and the number of goodquality embryos (or the number of fertilized oocytes) as the study primary outcome. Setting the power of study at $80 \%$ and alpha at 0.05 ( 2 tailed), we needed 80 cases to detect a minimally clinically significant correlation coefficient of 0.3. Sample size calculation was done using the IBM SPSS SamplePower software, release 3.0.1 (IBM Corp., Armonk, NY, USA).

\section{Statistical analysis}

The normal distribution of continuous data was assessed by the Anderson-Darling test (in addition to Q-Q plot). In turn, the description of data was as mean (SD) or median (range). Qualitative data were described in the form of count (percentage). Correlation between vitamin D level and the number of retrieved number of fertilized eggs, number of grade one embryos, and number of implanted embryos was done using Pearson correlation. Afterwards, multivariable regression analysis was done to calculate the coefficient of the relation between serum $25(\mathrm{OH}) \mathrm{D}$ vitamin level and the number of retrieved oocytes adjusting for possible confounders, namely, age, BMI, and type of ovulation-triggering agent (HCG vs $\mathrm{GnRH}$ agonist). Another multivariable regression analysis was done to assess the relation between vitamin level and the number of fertilized oocytes adjusting for the same previous confounding factors. In addition, logistic regression was performed to measure the odds ratio of occurrence of chemical and clinical pregnancy in relation to the vitamin level. 95\% confidence intervals (CI) were described for all applicable statistics. $P$ value <
0.05 was considered significant. Statistical analysis was done using the SPSS software, version 23 (IBM Corp., Armonk, NY, USA).

\section{Results}

A flow chart of the study population is presented in (Fig. 1). A total of 113 PCOS patients in the age of 20-39 were assessed for eligibility. Eighty women were eligible and accepted to participate. For all cases, the primary outcomes (number of retrieved and fertilized oocytes) were recorded.

The median (range) of age and BMI were $32(20,32)$ years and $27(24,29)$, respectively. Most of our study cases had primary infertility $(n=74 ; 92.5 \%)$ and irregular menstruation $(n=48,60 \%)$ (Table 1$)$.

As regards the ICSI cycle characteristics, most of the patients took HCG for triggering ovulation $(n=71$, $78.8 \%$ ), while the remaining proportion had $\mathrm{GnRH}$ agonist $(n=9,11.3 \%)$. The medians (range) of the number of retrieved and fertilized oocytes were $12(4,35)$ and $7(1$, $20)$, respectively, with a fertilization rate of $80 \%(13 \%$, $100 \%)$. No transfer with freezing of all embryos occurred in 6 cases $(8 \%)$ while the remaining women had their embryo transfer at day 3, $n=69$ (93.4\%), and day $2, n=$ $5(6.8 \%)$. Sixty-five percent of the cases had a transfer of 3 grade 1 embryos, while others had less number of grade 1 embryos. Biochemical pregnancy occurred in 31 out of 74 cases who did an embryo transfer (41.9\%). However, gestational sac with a fetal pulsation was detected in 27 patients (36.5\%). Most women had one gestational sac, and 3 cases (11.1\%) had two sacs. Only one case developed moderate OHSS which resolved on follow-up without a need for hospital admission (Table 2).

Serum $25(\mathrm{OH}) \mathrm{D}$ vitamin level was mostly in the deficient category, $n=72(90 \%)$, while the remaining patients, $n=8(10 \%)$, had insufficient levels of the vitamin. None of our PCOS cases had replete vitamin D status (Table 3).

Regarding the study primary outcomes; vitamin D was found to be correlated to both the number of retrieved and fertilized oocytes $(r=0.35,95 \%$ CI $0.15,0.53, P=$ $0.001 ; r=0.33,95 \%$ CI $0.03,0.57, P=0.03$, respectively). After adjusting for age, BMI, and type of ovulationtriggering agent in regression analysis, serum vitamin $\mathrm{D}$ level was still significantly correlated to the number of oocytes (coefficient $0.47 ; 95 \%$ CI $0.1,0.9 ; P=0.018$ ) and to the number of fertilized eggs (coefficient $0.3 ; 95 \% \mathrm{CI}$ $0.02,0.58 ; P=0.03$ ). This means with each $2 \mathrm{ng} / \mathrm{mL}$ increase in serum $25(\mathrm{OH})$ D vitamin level, around one more egg will be retrieved. In addition, there will be one more additional fertilized oocyte with each $3 \mathrm{ng} / \mathrm{mL}$ in the vitamin level (Table 4, Figs. 2 and 3). However, there was no significant correlation between the vitamin level and the occurrence of chemical or clinical pregnancy (Table 4). 


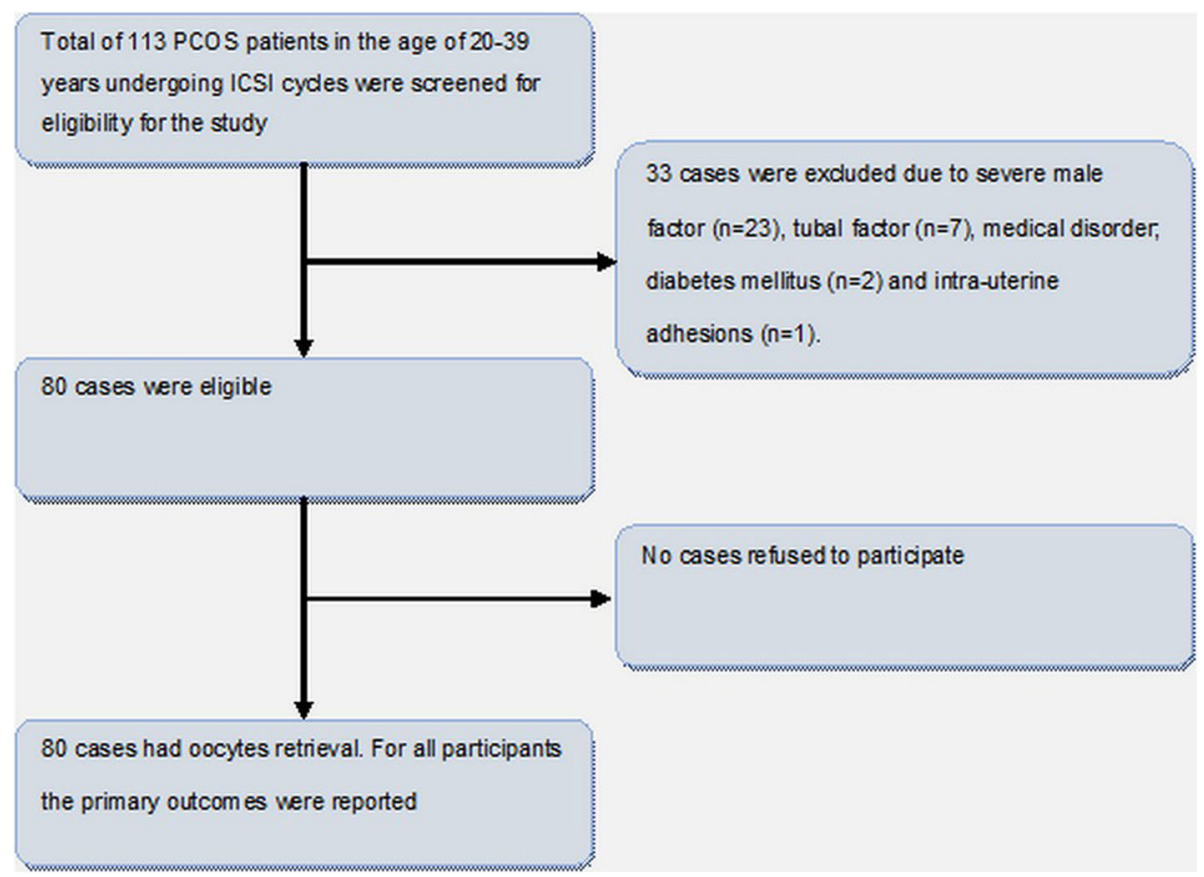

Fig. 1 Flow chart of the study population

\section{Discussion}

The present study demonstrated that 72 (90\%) of our PCOS patients undergoing ICSI trials had deficient status of serum $25(\mathrm{OH})$ D vitamin. This percentage was slightly higher than another study done by Thomson et al. who observed that up to $85 \%$ of ladies with PCOS have serum level of vitamin $D$ that is below $20 \mathrm{ng} / \mathrm{mL}$ [18]. However, not all studies have shown a correlation

Table 1 General and clinical characteristics of the study population

\begin{tabular}{ll}
\hline Characteristic & Study population, $n=80$ \\
\hline Age (years) & $32(20,39)$ \\
Type of infertility & $74(92.5 \%)$ \\
$\quad$ Primary & $6(7.5 \%)$ \\
$\quad$ Secondary & $4(2,10)$ \\
Duration of infertility (years) & \\
Previous IVF/ICSI failure & $68(85 \%)$ \\
No previous failure & $8(10 \%)$ \\
1 failure & $2(2.5 \%)$ \\
2 failures & $2(2.5 \%)$ \\
3 failures & $27(24,29)$ \\
BMI (kg/m $\left.{ }^{2}\right)$ & \\
Regularity of menstruation & $48(60 \%)$ \\
Irregular & $32(40 \%)$ \\
Regular & \\
\hline
\end{tabular}

Values are in the form of median (range) or count (percent) between derangement in vitamin $\mathrm{D}$ level and the incidence of PCOS [19]. That correlation between vitamin D deficiency and PCOS may be due to the effects of vitamin D receptors on LH and sex hormone-binding globulin levels, the incidence of insulin resistance, testosterone levels, and aromatase gene expression [9-14]. Moreover, the vitamin D status in Egypt was recently investigated in the general female population [20], and it was found that the prevalence of VD deficiency is $72 \%$ in childbearing age. This may be due to different lifestyle factors (sunlight exposure, sunscreen application, and deficient diet) making VD deficiency endemic in our country.

As regards the study primary outcomes, the number of retrieved oocytes and fertilized ones was positively correlated with serum VD level. That relation was still significant after adjusting for possible confounders signifying the independence of VD in the affection of the number of collected and fertilized oocytes. The plausible explanation may be that VD acts as a transcription factor to regulate the expression of the CYP19 gene, which encodes aromatase, an essential enzyme in the production of estrogen [21]. In addition, vitamin D is involved in the regulation of anti-Müllerian hormone (AMH) [7] and follicle-stimulating hormone [8]. Moreover, the association between VD deficiency and various metabolic disturbances in PCOS including insulin resistance may explain (at least partly) the impaired follicular growth [9-14, 22-27]. In accordance with our results, vitamin D deficiency $(25 \mathrm{nmol} / \mathrm{L}$ or, $10 \mathrm{ng} / \mathrm{mL}$ ) was found to be associated with lower rates of follicle development and 
Table 2 ICSI cycle characteristics for the study population

\begin{tabular}{|c|c|}
\hline Characteristic & Descriptive measure \\
\hline Serum estradiol at the day of triggering of ovulation $(\mathrm{pg} / \mathrm{mL})$ & $3211(1654,6211)$ \\
\hline \multicolumn{2}{|l|}{ Ovulation triggering agent } \\
\hline HCG & $71(88.7 \%)$ \\
\hline GnRH agonist (triptorelin) $0.2 \mathrm{mg}$ & $9(11.3 \%)$ \\
\hline Number of retrieved oocytes & $12(4,35)$ \\
\hline Number of fertilized oocytes & $7(1,20)$ \\
\hline Fertilization rate ${ }^{a}$ & $80 \%(13 \%, 100 \%)$ \\
\hline \multicolumn{2}{|l|}{ Embryo transfer } \\
\hline Fresh embryo transfer & $74(82 \%)$ \\
\hline No embryo transfer (freezing of all embryos) & $6(8 \%)$ \\
\hline \multicolumn{2}{|l|}{ Day of embryo transfer (number $=74$ cases) } \\
\hline Day 3 & $69(93.2 \%)$ \\
\hline Day 2 & $5(6.8 \%)$ \\
\hline \multicolumn{2}{|l|}{ Number of transferred embryos (number $=74$ cases) ${ }^{b}$} \\
\hline 1 embryo & $3(4 \%)$ \\
\hline 2 embryos & $6(8 \%)$ \\
\hline 3 embryos & $65(88 \%)$ \\
\hline \multicolumn{2}{|l|}{ Number of transferred grade 1 embryos (number $=74$ cases) ${ }^{b}$} \\
\hline No grade 1 embryos & $5(6.8 \%)$ \\
\hline 1 embryo & $5(6.8 \%)$ \\
\hline 2 embryos & $9(12.2 \%)$ \\
\hline 3 embryos & $55(74.2 \%)$ \\
\hline \multicolumn{2}{|l|}{ 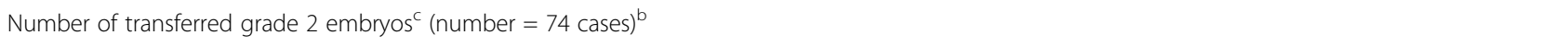 } \\
\hline No grade 2 embryos & $64(86.5 \%)$ \\
\hline 1 embryo & $3(4 \%)$ \\
\hline 2 embryos & $2(2.7 \%)$ \\
\hline 3 embryos & $5(6.8 \%)$ \\
\hline Chemical pregnancy rate (number $=74$ cases) & $31(41.9 \%)$ \\
\hline Clinical pregnancy rate (number $=74$ cases) & $27(36.5 \%)$ \\
\hline \multicolumn{2}{|l|}{ Number of implanted embryos (number = 27 clinical pregnancies) } \\
\hline One sac & $24(88.9 \%)$ \\
\hline Two sacs & $3(11.1 \%)$ \\
\hline Moderate OHSS & $1(1.25 \%)$ \\
\hline
\end{tabular}

Values are in the form of median (range) or count (percent)

HCG human chorionic gonadotropin, GnRH gonadotropin-releasing hormone

${ }^{a}$ Calculated as the number of fertilized embryos divided by the number injected oocytes for each patient

${ }^{\mathrm{b}}$ Number of patients who did an embryo transfer

'None of the study population had a transfer of grade 3 or 4 embryos

Table 3 Serum vitamin D levels

\begin{tabular}{lll}
\hline Characteristic & Descriptive measure & $95 \% \mathrm{Cl}$ \\
\hline $25(\mathrm{OH})$ vitamin D level $(\mathrm{ng} / \mathrm{mL})$ & $12.5 \pm 5$ & $(11.2,13.8)^{\mathrm{a}}$ \\
Vitamin D replete $(>30 \mathrm{ng} / \mathrm{mL})$ & $0(0 \%)$ & 0 \\
Vitamin D sufficient $(20-30 \mathrm{ng} / \mathrm{mL})$ & $8(10 \%)$ & $(4.4 \%, 18.8 \%)^{\mathrm{b}}$ \\
Vitamin D deficient $(<20 \mathrm{ng} / \mathrm{mL})$ & $72(90 \%)$ & $(81 \%, 95.5 \%)^{\mathrm{b}}$
\end{tabular}

Values are in the form of mean \pm SD or count (percentage)

${ }^{a}$ Confidence interval for the mean vitamin D level

${ }^{\mathrm{b}}$ Confidence interval for the percentage 
Table 4 Correlations between serum $25(\mathrm{OH})$ vitamin D and the number of retrieved and fertilized oocytes, and other ICSI cycle outcomes

\begin{tabular}{lll}
\hline Variables & Correlation coefficient $(95 \% \mathrm{Cl})$ & $P$ value \\
\hline Vitamin D vs number of retrieved oocytes & $r=0.35(0.15,0.53)^{\mathrm{a}}$ & $0.001^{*}$ \\
& $0.07(0.1,0.9)^{\mathrm{b}}$ & $0.018^{*}$ \\
Vitamin D vs number of fertilized oocytes & $r=0.33(0.03,0.57)^{\mathrm{a}}$ & $0.03^{*}$ \\
& $0.3(0.02,0.58)^{\mathrm{b}}$ & $0.03^{*}$ \\
Vitamin D vs number of implanted embryos & $-0.032(-0.26 \text { to } 0.12)^{\mathrm{a}}$ & 0.7 \\
& $0.01(-0.017,0.03)^{\mathrm{b}}$ & 0.57 \\
Vitamin D vs number of grade 1 embryos & $0.01(-0.22 \text { to } 0.24)^{\mathrm{a}}$ & 0.9 \\
& $0.01(-0.015,0.03)^{\mathrm{b}}$ & 0.5 \\
Variables & 0 Odds ratio $(95 \% \mathrm{Cl})$ & $P$ value \\
Vitamin D vs chemical pregnancy & $1.01(0.9,1.09)^{\mathrm{c}}$ & 0.3 \\
Vitamin D vs clinical pregnancy & $1.04(0.95,1.14)^{\mathrm{c}}$ & 0.4 \\
\hline
\end{tabular}

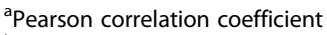

${ }^{b}$ Coefficient in multivariable regression analysis adjusting for possible confounders, namely, age, BMI, and type of ovulation-triggering agent (HCG vs GnRH agonist)

'Logistic regression for clinical and chemical pregnancy as response variables vs serum $25(\mathrm{OH}) \mathrm{D}$ vitamin level as the independent variables with inclusions of the following confounders in the model: age, BMI, type and duration of infertility, previous IVF failure, and the type of triggering agent

*Statistical significance

pregnancy after ovarian stimulation with $50 \mathrm{mg}$ clomiphene citrate [28].

It has been suggested that VD plays a role in the decidual function and embryo implantation [29]. Therefore, in the last few years, due to emerging evidence of the role of VD in female human reproduction including implantation, there was an increasing interest in investigating the correlation between vitamin $\mathrm{D}$ deficiency and in vitro fertilization outcome [30-32]. Some investigators have found better IVF outcomes in cases of sufficient VD status [33-35], whereas other studies failed to show any correlation between serum or follicular fluid VD level and pregnancy outcome after IVF/ICSI [29, 36-39]. However, no similar study assessed the effect of derangement of serum VD level on ICSI outcome in the particular category of PCOS females.

However, our study has its limitations. Despite the power of the study was enough for the study's primary aims, namely correlation of serum $25(\mathrm{OH})$ D vitamin level with a number of retrieved and fertilized oocytes, it was not enough to detect a statistically significant difference in pregnancy rates (as secondary outcomes).

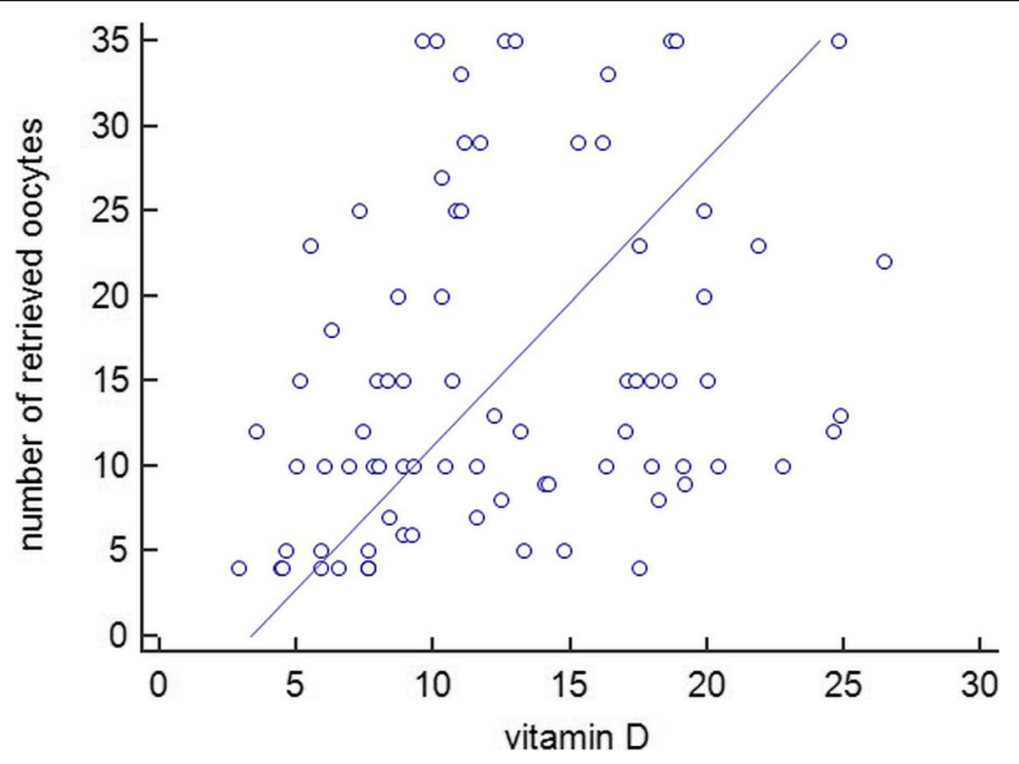

Fig. 2 Correlation of serum $25(\mathrm{OH}) \mathrm{D}$ vitamin level to the number of retrieved oocytes 


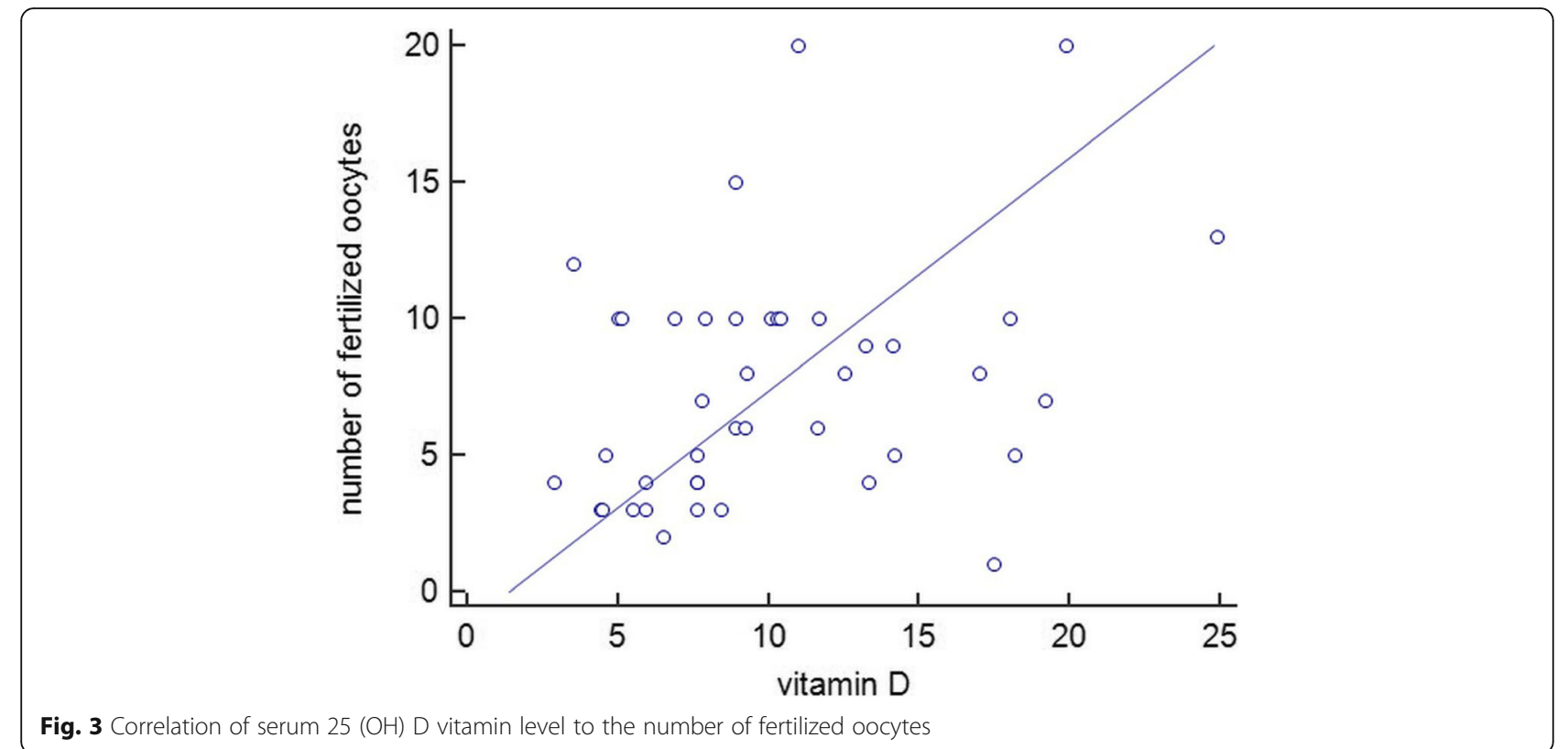

Although the absence of such correlations was in agreement with other studies [29, 36-39], we could not exclude the probable effect of VD on implantation and pregnancy as these outcomes were secondary outcomes. Moreover, those studies that failed to prove this correlation assessed VD level in the general IVF population (not specifically PCOS patients) and compared the pregnancy in different categories of VD status. It may be that the absolute level of VD affects the pregnancy outcome. In turn, statistically, dealing with VD as a continuous predictor variable of IVF outcome (as we did in the present study) may elucidate the actual effect of vitamin D on different cycle parameters. Therefore, further studies with adequate power to detect an effect on pregnancy rate are needed. In addition, studies are needed to evaluate the effect of vitamin D supplementation on IVF/ICSI pregnancy outcomes in those who are deficient or insufficient.

\section{Conclusion}

In conclusion, based on the study results, VD was positively correlated with the number of retrieved and the number of fertilized oocytes in PCOS patients undergoing ICSI cycles. According to the regression analysis adjusting for possible confounders, with each increase of serum $25(\mathrm{OH})$ of $2 \mathrm{ng} / \mathrm{mL}$, there was one more retrieved oocyte. In addition, there was an addition of one fertilized oocyte with each $3 \mathrm{ng} / \mathrm{mL}$ increase in serum VD level.

\section{Abbreviations}

AMH: Anti-Müllerian hormone; BMI: Body mass index; Cl: Confidence intervals; GnRH: Gonadotropin-releasing hormone antagonist; HCG: Human chorionic gonadotropin; HMG: Human menopausal gonadotropin;
OHSS: Ovarian hyperstimulation syndrome; PCOS: Polycystic ovary syndrome; VD: Vitamin D

\section{Acknowledgements}

The authors acknowledge the staff department of IVF at Cairo University for the help of this research to be accomplished

\section{Authors' contributions}

EFO: data collection and analysis, planning of the study protocol, revision of the study. AR: idea of the work, planning of the protocol, revision of the study. AS: idea of the work, planning of the protocol, revision of the study. NF: data collection. MS: analysis and revision of the study. HB: study protocol and data collection. MFS: data collection and revision of the study. All authors have read and approved the final manuscript.

\section{Funding}

None

Availability of data and materials

The authors confirm the availability of data and materials.

\section{Ethics approval and consent to participate}

Ethics approval was taken for this study by the Kasralainy Obstetrics and Gynecology Department (20161101). The consent to participate was in a written form.

\section{Consent for publication}

The authors confirm giving consent for publication.

\section{Competing interests}

The authors confirm the absence of competing interests for this study.

\section{Author details}

'Department of Obstetrics and Gynecology, Faculty of Medicine, Cairo University, Al-Saray St., Al-Manial, Cairo 11956, Egypt. ${ }^{2}$ Department of Clinical and Chemical Pathology, Cairo University, Cairo, Egypt.

Received: 20 September 2019 Accepted: 18 June 2020 Published online: 29 June 2020

\section{References}

1. Bellver J, Rodriguez-Tabernero L, Robles A et al (2018) Polycystic ovary syndrome throughout a woman's life. J Assist Reprod Genet 35(1):25-39 
2. Bozdag G, Mumusoglu S, Zengin D, Karabulut E, Yildiz BO (2016) The prevalence and phenotypic features of polycystic ovary syndrome: a systematic review and meta-analysis. Hum Reprod 31(12):2841-2855

3. Sanad AS (2014) Prevalence of polycystic ovary syndrome among fertile and infertile women in Minia Governorate, Egypt. Int J Gynaecol Obstet 125(1): 81-82

4. Thessaloniki ESHRE/ASRM-Sponsored PCOS Consensus Workshop Group (2008) Consensus on infertility treatment related to polycystic ovary syndrome. Hum Reprod 23(3):462-477

5. Balen AH, Morley LC, Misso M et al (2016) The management of anovulatory infertility in women with polycystic ovary syndrome: an analysis of the evidence to support the development of global WHO guidance. Hum Reprod Update 22(6):687-708

6. Nandi A, Sinha N, Ong E, Sonmez H, Poretsky L (2016) Is there a role for vitamin D in human reproduction? Horm Mol Biol Clin Invest 25(1):15-28

7. Dennis NA, Houghton LA, Jones GT, van Rij AM, Morgan K, McLennan IS (2012) The level of serum anti-Mullerian hormone correlates with vitamin D status in men and women but not in boys. J Clin Endocrinol Metab 97(7): 2450-2455

8. Irani M, Merhi Z (2014) Role of vitamin D in ovarian physiology and its implication in reproduction: a systematic review. Fertil Steril 102(2):460-468 e463

9. Yildizhan R, Kurdoglu M, Adali E et al (2009) Serum 25-hydroxyvitamin D concentrations in obese and non-obese women with polycystic ovary syndrome. Arch Gynecol Obstet 280(4):559-563

10. Kotsa K, Yavropoulou MP, Anastasiou O, Yovos JG (2009) Role of vitamin D treatment in glucose metabolism in polycystic ovary syndrome. Fertil Steri 92(3):1053-1058

11. Selimoglu H, Duran C, Kiyici S et al (2010) The effect of vitamin D replacement therapy on insulin resistance and androgen levels in women with polycystic ovary syndrome. J Endocrinol Investig 33(4):234-238

12. Zadeh-Vakili A, Ramezani Tehrani F, Daneshpour MS, Zarkesh M, Saadat N, Azizi F (2013) Genetic polymorphism of vitamin D receptor gene affects the phenotype of PCOS. Gene. 515(1):193-196

13. Irani M, Minkoff $H$, Seifer DB, Merhi Z (2014) Vitamin D increases serum levels of the soluble receptor for advanced glycation end products in women with PCOS. J Clin Endocrinol Metab 99(5):E886-E890

14. Figurova J, Dravecka I, Javorsky M, Petrikova J, Lazurova I (2016) Prevalence of vitamin D deficiency in Slovak women with polycystic ovary syndrome and its relation to metabolic and reproductive abnormalities. Wien Klin Wochenschr 128(17-18):641-648

15. (2008) STROBE statement--checklist of items that should be included in reports of observational studies (STROBE initiative). Int J Public Health 53(1): $3-4$

16. Rotterdam ESHRE/ASRM-Sponsored PCOS Consensus Workshop Group (2004) Revised 2003 consensus on diagnostic criteria and long-term health risks related to polycystic ovary syndrome (PCOS). Hum Reprod 19(1):41-47

17. Practice Committee of the American Society for Reproductive Medicine (2016) Prevention and treatment of moderate and severe ovarian hyperstimulation syndrome: a guideline. Fertil Steril 106(7):1634-1647

18. Thomson RL, Spedding S, Buckley JD (2012) Vitamin D in the aetiology and management of polycystic ovary syndrome. Clin Endocrinol 77(3):343-350

19. Moini A, Shirzad N, Ahmadzadeh M, Hosseini R, Hosseini L, Sadatmahalleh SJ (2015) Comparison of 25-hydroxyvitamin D and calcium levels between polycystic ovarian syndrome and normal women. Int J Fertility Steril 9(1):1-8

20. Botros RM, Sabry IM, Abdelbaky RS, Eid YM, Nasr MS, Hendawy LM (2015) Vitamin D deficiency among healthy Egyptian females. Endocrinol Nutr 62(7):314-321

21. Kinuta K, Tanaka H, Moriwake T, Aya K, Kato S, Seino Y (2000) Vitamin D is an important factor in estrogen biosynthesis of both female and male gonads. Endocrinology. 141(4):1317-1324

22. Van Belle TL, Gysemans C, Mathieu C (2013) Vitamin D and diabetes: the odd couple. Trends Endocrinol Metab 24(11):561-568

23. Mathieu C (2015) Vitamin D and diabetes: where do we stand? Diabetes Res Clin Pract 108(2):201-209

24. Colonese F, Laganà AS, Colonese E, Sofo V, Salmeri FM, Granese R, Triolo O (2015) The pleiotropic effects of vitamin D in gynaecological and obstetric diseases: an overview on a hot topic. Biomed Res Int 2015:986281

25. Teegarden D, Donkin SS (2009) Vitamin D: emerging new roles in insulin sensitivity. Nutr Res Rev 22(1):82-92
26. Muscogiuri G, Policola C, Prioletta A et al (2012) Low levels of 25(OH)D and insulin-resistance: 2 unrelated features or a cause-effect in PCOS? Clin Nutr 31(4):476-480

27. Jia XZ, Wang $Y M$, Zhang $N$ et al (2015) Effect of vitamin $D$ on clinical and biochemical parameters in polycystic ovary syndrome women: a metaanalysis. J Obstet Gynaecol Res 41(11):1791-1802

28. Ott J, Wattar L, Kurz C et al (2012) Parameters for calcium metabolism in women with polycystic ovary syndrome who undergo clomiphene citrate stimulation: a prospective cohort study. Eur J Endocrinol 166(5):897-902

29. Pacis MM, Fortin CN, Zarek SM, Mumford SL, Segars JH (2015) Vitamin D and assisted reproduction: should vitamin $D$ be routinely screened and repleted prior to ART? A systematic review. J Assist Reprod Genet 32(3):323335

30. Vanni VS, Vigano P, Somigliana E et al (2014) Vitamin D and assisted reproduction technologies: current concepts. Reprod Biol Endocrinol 12:47

31. Paffoni A, Ferrari S, Vigano $P$ et al (2014) Vitamin D deficiency and infertility: insights from in vitro fertilization cycles. J Clin Endocrinol Metab 99(11): E2372-E2376

32. Lv SS, Wang JY, Wang XQ, Wang Y, Xu Y (2016) Serum vitamin D status and in vitro fertilization outcomes: a systematic review and meta-analysis. Arch Gynecol Obstet 293(6):1339-1345

33. Ozkan S, Jindal S, Greenseid K et al (2010) Replete vitamin D stores predict reproductive success following in vitro fertilization. Fertil Steril 94(4):13141319

34. Anifandis GM, Dafopoulos K, Messini Cl et al (2010) Prognostic value of follicular fluid $25-\mathrm{OH}$ vitamin D and glucose levels in the IVF outcome. Reprod Biol Endocrinol 8:91

35. Garbedian K, Boggild M, Moody J, Liu KE (2013) Effect of vitamin D status on clinical pregnancy rates following in vitro fertilization. CMAJ Open 1(2): E77-E82

36. Aleyasin A, Hosseini MA, Mahdavi A et al (2011) Predictive value of the level of vitamin $D$ in follicular fluid on the outcome of assisted reproductive technology. Eur J Obstet Gynecol Reprod Biol 159(1):132-137

37. Rudick BJ, Ingles SA, Chung K, Stanczyk FZ, Paulson RJ, Bendikson KA (2014) Influence of vitamin $D$ levels on in vitro fertilization outcomes in donorrecipient cycles. Fertil Steril 101(2):447-452

38. Firouzabadi RD, Rahmani E, Rahsepar M, Firouzabadi MM (2014) Value of follicular fluid vitamin $D$ in predicting the pregnancy rate in an IVF program. Arch Gynecol Obstet 289(1):201-206

39. Franasiak JM, Molinaro TA, Dubell EK et al (2015) Vitamin D levels do not affect IVF outcomes following the transfer of euploid blastocysts. Am J Obstet Gynecol 212(3):315.e311-315.e316

\section{Publisher's Note}

Springer Nature remains neutral with regard to jurisdictional claims in published maps and institutional affiliations.

\section{Submit your manuscript to a SpringerOpen ${ }^{\circ}$ journal and benefit from:}

- Convenient online submission

- Rigorous peer review

- Open access: articles freely available online

- High visibility within the field

- Retaining the copyright to your article

Submit your next manuscript at $>$ springeropen.com 